\title{
La construcción y ampliación de los regadíos tradicionales e históricos en la Vega Alta de Segura: sucesión de azudes y acequias, artilugios hidráulicos escalonados y motores de elevación de aguas
}

\author{
José María Gómez Espín \\ Departamento de Geografía. Universidad de Murcia \\ espin@um.es
}

\begin{abstract}
Resumen. Para aprovechar en regadío las aguas del Segura en su tramo alto (del nacimiento en Pontones a la Contraparada, azud del inicio de la Huerta de Murcia), los grupos humanos se las han ingeniado mediante una serie de técnicas, para derivar el agua por las márgenes (sangrado del Segura) y regar las tierras más próximas, con una sucesión de azudes y acequias escalonados según la pendiente. Posteriormente se eliminaron algunos de los azudes y se prolongaron las acequias, e incluso se unieron varios de estos sistemas hidráulicos una vez que fue posible "fortificar" los azudes y atravesar con minados los espolones rocosos de los estrechos.

Para la conquista de las laderas, que quedan por encima del trazado de las acequias, se instalan una serie de artilugios elevadores de agua (norias, ceñas, artes, bombas de mano, etc.), de los que restan algunos de ellos todavía funcionando, como las ruedas de corriente baja (en Abarán cuatro de ellas). A finales del siglo XIX y primeros años del siglo XX, varios de estos artilugios de elevación hidráulica son sustituidos por máquinas de vapor y motores (de aceite pesado, de gas pobre, de gasoil, de gasolina y, electromotores) que elevan más agua a mayor altura, e incluso pueden sacarla del reducido marco del valle (como la elevación del Motor Resurrección y otros.).

Pasar del riego eventual al permanente y ampliar los espacios regados, fue posible gracias a la red de embalses en el río Segura (Fuensanta, Cenajo) y en afluentes como el Mundo (Talave, Camarillas), que lo convierten en uno de los ríos más regulados de la Cuenca Mediterránea, y alteran su régimen natural, adaptándolo a las demandas del cultivo en sus vegas. Figura toda una tipología de regadíos según el origen del agua: superficiales de escorrentía del Segura y su red de afluentes, de fuentes y manantiales, y de subálveos y acuíferos profundos. Según la localización en el valle, se distinguen: riegos bajo acequia (sotos del río y terrazas próximas), riegos por elevación con artilugios tradicionales (terrazas hasta los 25 metros de altura), y con grupos motobomba (partes más altas del valle e incluso fuera de él).
\end{abstract}

Palabras clave: Azud, acequia, rueda hidráulica, grupo motobomba, regadío tradicional e histórico, Vega Alta del Segura.

\begin{abstract}
The extension of historical and traditional irrigation in La Vega Alta de Segura: Succession of irrigation dams and irrigation channels, stepped water devices, and mechanically-powered water lifting devices. To use the waters from the River Segura at its high course (from the source in Pontones to La Contraparada, dam at the beginning of the Huerta de Murcia) for irrigation, human groups have devised a series of techniques to divert water along the banks ("draining" of the Segura) to irrigate the nearest land: through a succession of irrigation dams and channels stepped according to the slope. Later, some of the dams were removed and the channels extended, and even several of these water systems were joined once it was possible to "strengthen" the dams and undermine the rocky spurs of the straits.

To conquer the slopes above the channel path, a series of water lifting devices were installed (different types of water wheels, hand pumps, etc.), some of which are still in use today, such as low current wheels (in Abarán there are four). At the end of the 19th century and in the early 20th, several of these water lifting devices were replaced by steam engines and other types of engines (heavy oil, producer gas, diesel, petrol, and electric motor) to lift the water higher, and even out of the limited framework of the valley (such as the "Motor Resurrección" and others).

It was possible to go from occasional to permanent irrigation and extend the irrigated areas thanks to the network of dams along the River Segura (Fuensanta, Cenajo) and tributaries like El Mundo (Talave, Camarillas), turning it into one of the most regulated rivers of the Mediterranean Basin, altering its natural regime, and adapting it to crop demands on its fertile plains. There is a whole typology of irrigation systems according to the origin of the water: surface runoff of the Segura and its network of tributaries, sources and springs, groundwaters and deep aquifers. According to their location in the valley, we have: low channel irrigation (river banks and nearby terraces), lift irrigation with traditional devices (terraces up to 25 metres high), and with pumping units (higher parts of the valley and even outside it).
\end{abstract}

Keywords: Dam, channel, water wheel, pumping unit, traditional and historical irrigation, Vega Alta del Segura. 


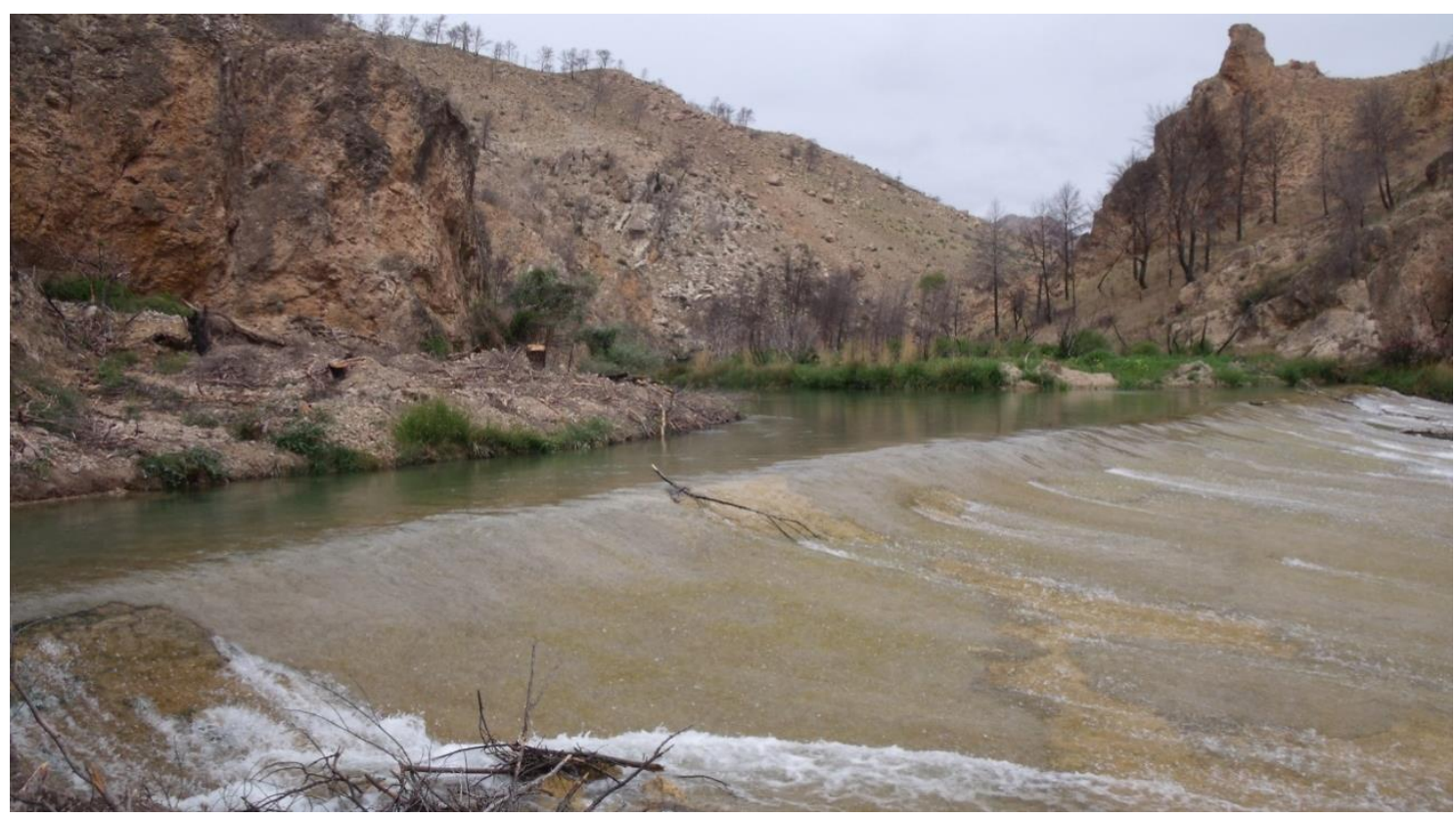

Fig.1. Estrecho del Rey o de Los Caballos. Presa de Rey, de su margen izquierda, toman las acequias de Maeso y Minas, y de la margen derecha, las acequias de Moharque y Torre

Arenas. (28/05/2014)

\section{Objeto y método}

Explicar las infraestructuras hidráulicas creadas para el regadío histórico del tramo murciano de la Vega Alta del Segura, es el objeto de esta investigación. Desde la metodología de la Geografía Regional y de la Ordenación del Territorio a escala subregional (comarcal); se aborda un estudio diacrónico y comparado para explicar tres modelos de regadío: riego bajo acequia, a pie, a portillo; riego por elevación con artilugios elevadores de agua, y riego por elevación con grandes máquinas hidráulicas y grupos motobomba. Una historia común de la relación hombre-medio en la que destacan: el régimen del Segura y la topografía del Valle, el "animus regandis" de los habitantes del valle fluvial, los sistemas hidráulicos de asociación de azud-acequias, y los ingenios de elevación de agua escalonados para la conquista de las laderas del valle.

\section{El área de estudio: el Valle del Segura en su tramo alto}

El Segura nace en el sitio denominado "Casa del Pinar Negro" en Pontones (Jaén) a 1.412,72 metros de altura sobre el nivel del mar. A lo largo de su recorrido hasta la desembocadura en Guardamar (más de 330 kilómetros), debe atravesar los relieves Béticos que tienen una dirección predominante NE-SW. Para ello aprovecha una red de fallas, dando origen a un valle en forma "de rosario", en el que se suceden estrechos (como el Cañón de Los Almadenes) y áreas de mayor amplitud (como la cubeta de Cieza). Desde el origen hasta dónde está la cerrada, en la que se levanta la presa para el embalse de Fuensanta, el río Segura lleva una dirección NW-SE, a partir de esta presa y hasta la del Rey adopta una dirección W-E, y de ésta hasta la Contraparadala NW-SE. Al penetrar en la 
Depresión Prelitoral cambia a la dirección SW-NE, que mantendrá hasta la desembocadura en el Mediterráneo.

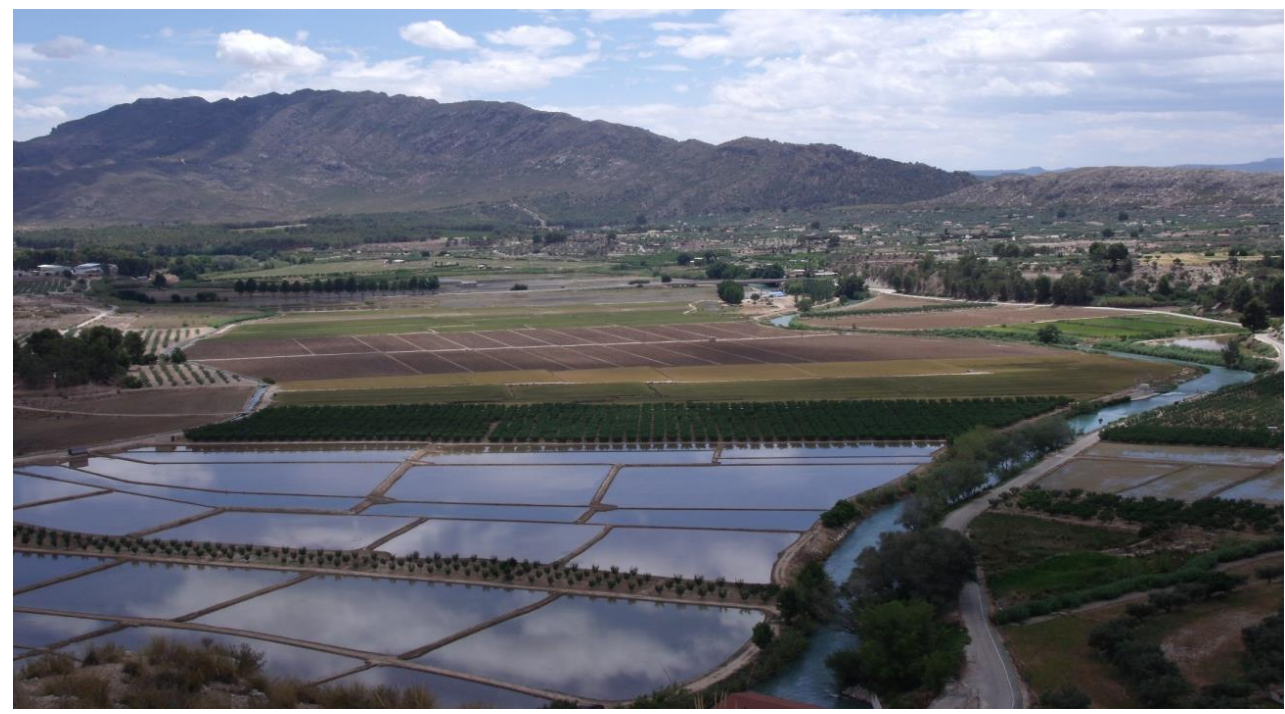

Fig.2. Sotos de Calasparra, regados por las aguas de la acequia de Berberín. (28/05/2014)

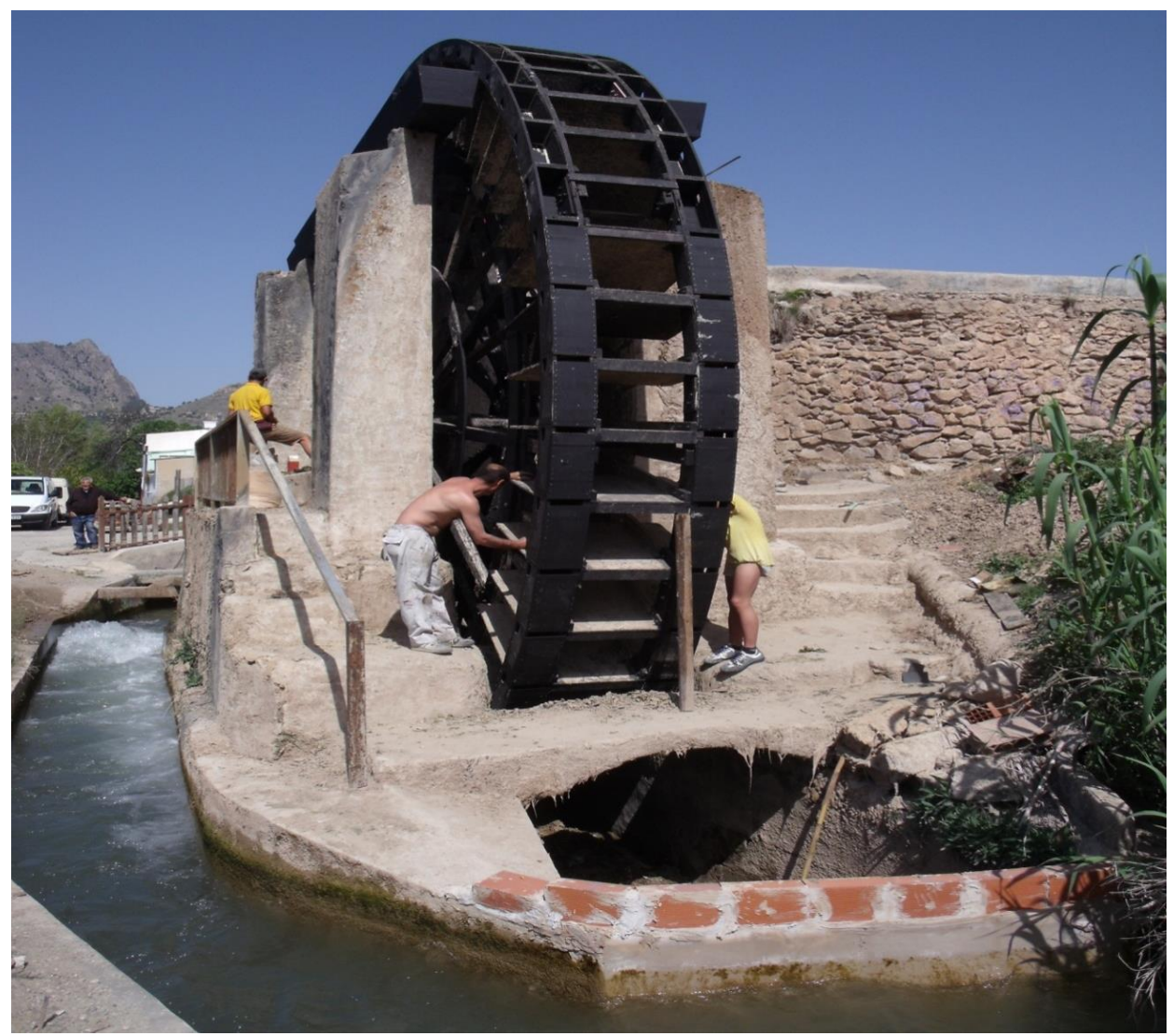

Fig.3. Reparaciones en la rueda de corriente baja "Noria Hoya de D. García”.(14/04/2014)

El tramo de Vega Alta del Segura, que se analiza en esta investigación, es de unos 147 kilómetros de su curso, el comprendido desde el pie de la Presa del Cenajo hasta el 
estrecho dónde se asienta la presa o azud de la Contraparada,que distribuye las aguas para el riego en la Huerta de Murcia. En este trayecto, aprovechando una serie de fallas, corta las alineaciones Prebéticas y Subbéticas, dando lugar a un valle disimétrico con estrechos como el del Cenajo, La Chamorra, del Rey o Los Caballos, Cañaverosa, cañón de Los Almadenes, El Menjú, Las Canales, Peña Negra, desfiladero del Solvente, Salto de la Novia, La MorraLos Baños, estrecho de Las Pudingas, etc. Y se abre en los corredores entre alineaciones, como en las cubetas u hoyas de El Salmerón, Calasparra, Cieza, Hoya de D.Garcia, Abarán, Blanca, Ojós-Villanueva-Ulea, Archena-La Algaida, vegas de Ceuti, Lorquí, Alguazas y Molina de Segura, etc.

\section{Modelos de captación, conducción y distribución del agua en la Vega Alta}

La construcción, consolidación y ampliación de las áreas regadas en la Vega Alta del Segura se ha realizado mediante la combinación de diversos modelos de derivar, captar-alumbrar y elevar el agua que se desea emplear en el regadío.

a) Modelo de derivación de aguas perennes concentradas en cursos de agua como los ríos. Es el caso del sangrado de Segura mediante una sucesión de sistemas de azud y acequia, escalonados según la pendiente. Corresponde al riego de superficies bajo la cota del trazado de la acequia "riegos bajo acequia". Se riegan sotos, rincones y terrazas fluviales próximas al cauce del río Segura.

b) Modelo de elevación de aguas de las acequias o del río para regar las laderas de los valles fluviales, el regadío por elevación. Inicialmente con aterrazamientos a los que se lleva el agua mediante ruedas y contraruedas, artilugios tradicionales como las ruedas de corriente baja, norias de tiro o de sangre, norias de cremallera, etc. Finalmente con grandes grupos de elevación de agua (electromotores) que elevan más caudal a cotas más altas, e incluso fuera del marco del Valle del Segura.

c) Modelo de puntos de agua, como los de fuentes y manantiales. Favorecidos por pozos horizontales (galerías) o simplemente que aprovechan la salida natural de un acuífero. La Fuente Grande de Ricote, La Fuente del Ojo en Cieza, La Fuente de Benito en Abarán, El Madroñal en Cieza, Los Baños en Archena, etc. Riego de oasis y abastecimiento de ganados y personas (uso doméstico).

d) Modelo de derivación de escorrentías intermitentes de ramblas y acondicionamiento de cauces como barrancos y cañadas. Los sistemas de asociación de presa de derivación y boquera para encauzar y distribuir turbiones y avenidas. Las presas de Arriba y Abajo en la rambla del Moro en el paraje del Román (Jumilla-Abarán), la presa y boquera del Barranco del Aljunzarejo (Cieza-Jumilla). Riego de secanos asistidos, riegos de alfait, riego eventual.

e) Modelo de extracción de aguas profundas. Sondeos y pozos en acuíferos. La sobreexplotación de algunos de ellos que seca nacimientos, fuentes y manantiales. La sobrexplotación del acuífero Ascoy-Sopalmo por "agronegocios" en los años sesenta y setenta del siglo XX como Nuevas Explotaciones de Aguas S.A. -NEASA, Explotaciones Santa Marta "Casablanca", El Aljunzarejo, El Hornillo, etc. Que acaban con salidas naturales como la Fuente del Ojo en Cieza y otras, pero crean nuevos espacios regados fuera de los regadíos históricos.

f) Modelo de consolidar regadíos tradicionales y crear nuevos regadíos mediante aguas trasvasadas al Sureste de España. El acueducto Tajo-Segura y el Postrasvase en la cuenca de 
Segura, en el Bajo Vinalopó y Bajo Almanzora. Su complemento mediante técnicas de desalación de recursos propios y de aguas residuales regeneradas para riego.

\section{Infraestructuras para el riego a pie, a portillo y bajo acequia. Riego por gravedad de sotos de río y terrazas próximas}

El estrecho marco del valle fluvial y la pendiente de este tramo del río, ha obligado para aprovechar sus aguas para riego o para fines energéticos, a escalonar una serie de presas o azudes, que permitieran retener y elevar el agua hasta que penetrase por los portillos abiertos en una o en las dos márgenes de la presa y del río. Inicialmente estos azudes eran simples estacadas de madera formando cajones que se rellenaban de piedras ${ }^{1}$. La mayor parte de estas pequeñas presas o azudes están situados a la salida de los estrechos. Las avenidas de Segura los destruían con facilidad, hasta la regulación del régimen del río tras la construcción de los grandes hiperembalses como los de Fuensanta y Cenajo. En los archivos municipales encontramos documentación de las quejas de los vecinos por las pérdidas que producían estas roturas de azudes y de buena parte de tomas y conducciones de las acequias, por lo que se practica la unión de sistemas de una misma margen reduciendo el número de azudes ${ }^{2}$.

También se fortifican los azudes y se prolongan las acequias atravesando mediante minado los relieves. Las avenidas extraordinarias, como la riada de San Rafael, tras las lluvias de los días 21, 22 y 23 de octubre de 1948, ocasionan toda una serie de roturas y desperfectos en los aprovechamientos de Segura como: destrucción total o parcial de las presas y obras de toma de las acequias, roturas del cajero de la acequia, y hundimiento total del cauce en parajes en los que la acequia discurre junto al río.

El número de sistemas de azud-acequia que se suceden en el tramo analizado, se inicia por los existentes al pie de la Presa del Embalse del Cenajo, en la margen izquierda (en adelante M.I.) la acequia del Cenajo, y en la margen derecha (en adelante M.D.) la acequia Picanas. Tras el estrecho de La Chamorra, se sitúa la presa del Hondón y por la M.I. discurren la acequia del Hondón y de ella la acequia de La Chamorra. Tras el estrecho del Rey o de Los Caballos se establece la presa del Rey de la que parten por su M.I. los heredamientos de Maeso y Minas, la acequia de Minas parte de la de Maeso, y por la M.D. la acequia de Torre Arenas y Moharque. A unos 150 kilómetros del origen del río Segura aparece la presa de Salmerón de la que parte en la M.D. la acequia de Salmerón, y de su cola arranca la acequia

\footnotetext{
${ }^{1}$ A.C.H.S. Signatura 758. 8 de noviembre de 1948. "La presa del Bayo, como todas las antiguas presas de riego de esta región, está formada por pilotaje trabado por medio de largueros y trabas transversales, que dividen la planta de la presa en una serie de recintos o cajones que se rellenan de mampostería en seco".

Arévalo Marco (1932-1933, p. 61): "Presa de Don Gonzalo, de Los Almadenes o de La Torre. Término de Cieza Distancia al origen 195,24 Km. En la margen derecha del río Segura y próximo al desagüe de los Almadenes y aguas debajo de él existe un enfaginado poco mayor que la mitad de la anchura del río que facilita la entrada de las aguas de aquel desagüe en una acequia llamada de Don Gonzalo o del Cañaveral... Antiguamente esta acequia tenía su origen en una presa que fue destruida por una crecida del río y que se sustituyó por el enfaginado que hoy existe al construirse el salto de los Almadenes “. Páginas 61 y 62. "Estacada de la Andelma. Término de Cieza. Distancia al origen 201,16 Km. Esta estacada que existía en la antigüedad y que fue destruida por una crecida está hoy sustituida por un enfaginado análogo al que da entrada a la Acequia de Don Gonzalo...”.

${ }^{2}$ Gómez Espín (1983a) Escritura otorgada el 25 de agosto de 1807, en Abarán, ante el escribano D. José Molina Gómez. “... que con el motivo de haberse roto la presa o azud de la toma de agua que tenía la villa de Blanca en esta jurisdicción para los regadíos y uso del molino, desde luego se trato de que no había necesidad de reedificarlas porque fácilmente podría venir agua suficiente para los dos pueblos por las minas y cauce que tenía Abarán, ...".
} 
de la Dehesa. Hasta aquí los sistemas de la M.D. correspondían al término murciano de Moratalla, y los de la M.I. al término albaceteño de Hellín.

\section{SANGRADO DEL SEGURA POR ACEQUIAS}

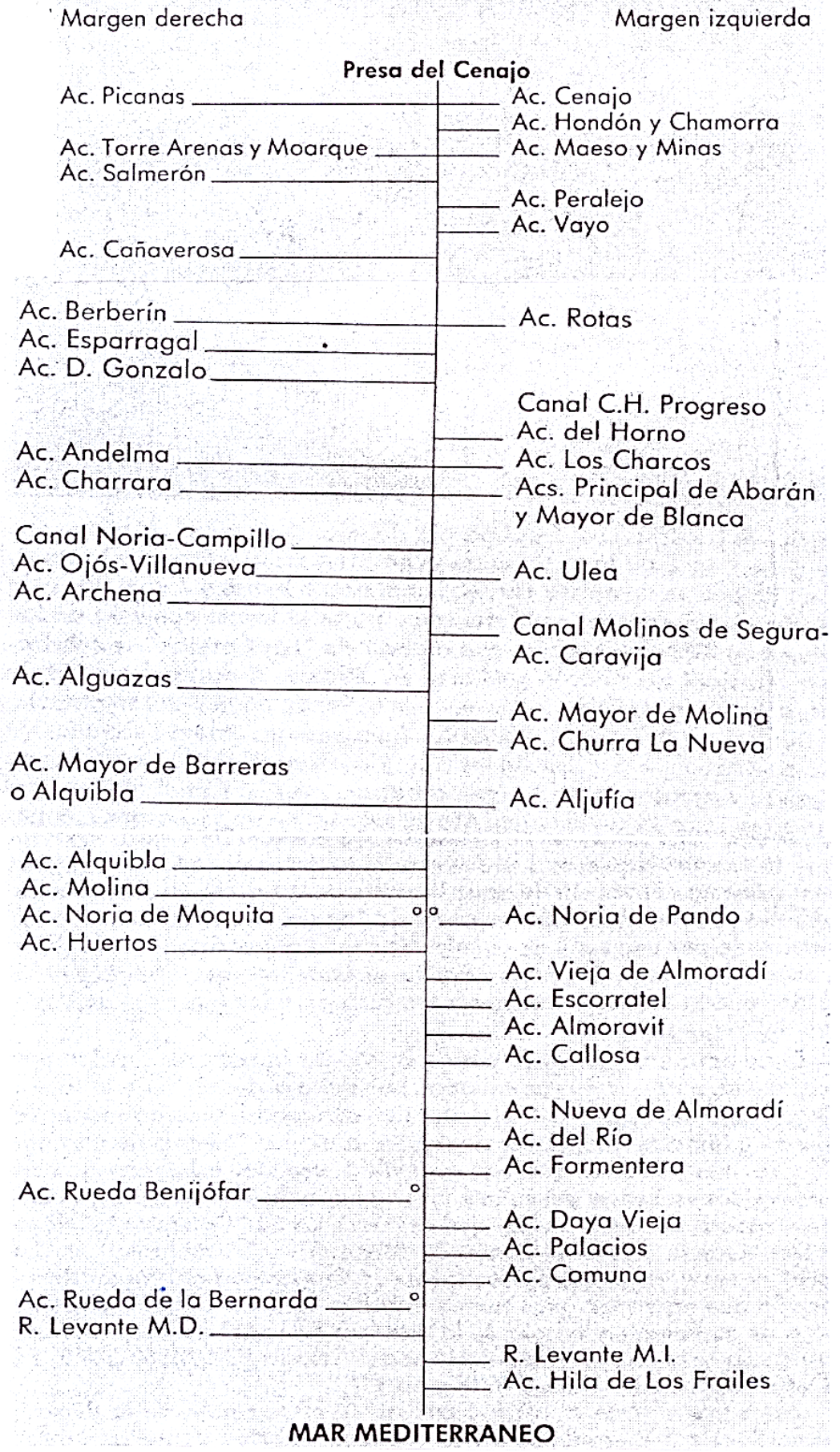

Fig.4. Sistemas de azud y acequia que se suceden en el río Segura. 


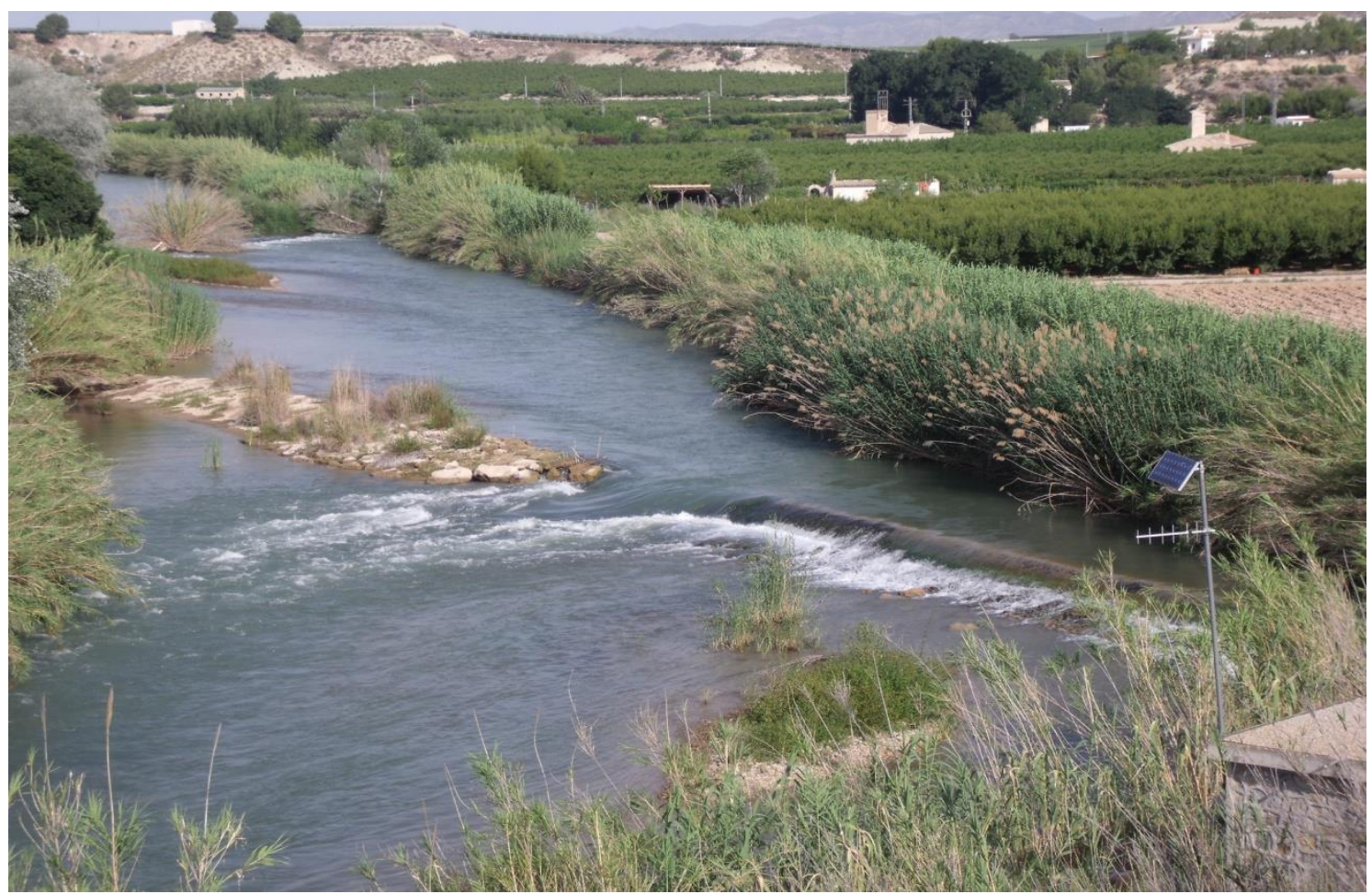

Fig.5. Azudes y tomas de las acequias de Los Charcos (M.I) y de Andelma (M.D). (20/06/2014).

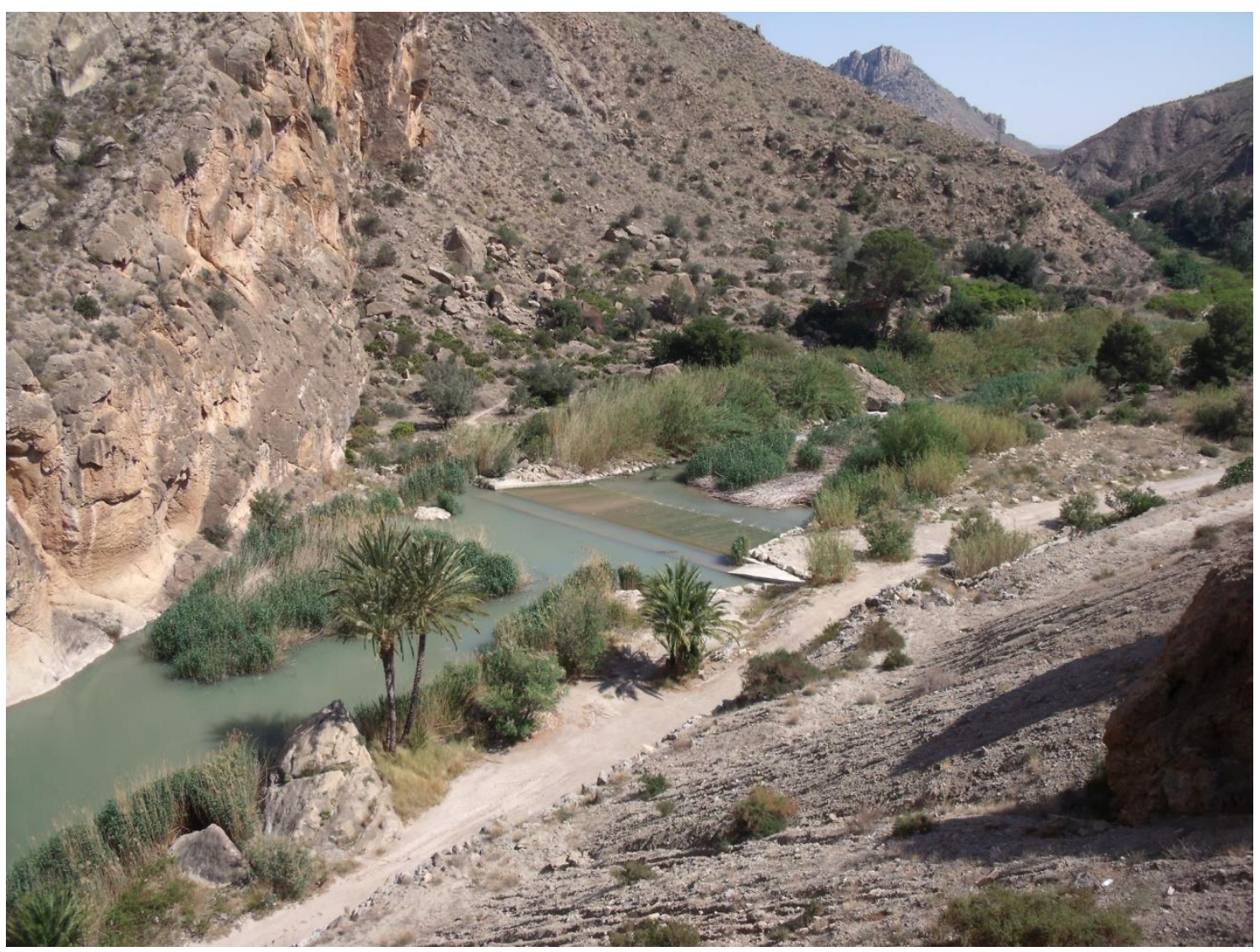

Fig.6. Estrecho de El Solvente. Antiguo azud de Ojós del que parte por su M.I., la acequia de Ulea y por la M.D.; la de Ojós y Villanueva (18/04/2014). 
En término de Calasparra figuran varios sistemas de azud-acequia, hay que destacar la presa o azud del Peralejo y el azud y acequia del Vayo en la M.I., y aguas abajo en la M.D. la presa y acequia de Cañaverosa. Esta última, desde su toma está cimbrada con más de un kilómetro de longitud y con varias lumbreras. También del otro extremo de la presa parte la galería que atraviesa los relieves hasta el salto hidroeléctrico de la Central de Cañaverosa, próxima al sistema de la presa de Rotas, en su M.I parte la acequia de Rotas y de la M.D. la acequia de Berberín. Finalmente en término de Calasparra y antes del estrecho de Almadenes, en la M.D. se sitúa la presa que actualmente desvía agua (río muerto) para el salto hidroeléctrico de la Central de la Esperanza y la acequia del Esparragal.

A partir de Los Almadenes, se inician los sistemas que sangran al Segura para el riego en término de Cieza, de su M.I. a partir del Borbotón el canal para salto hidroeléctrico de la Sociedad Riegos del Progreso (río muerto) y del que toma la acequia del Horno. En la M.D. aguas abajo de la Central de Almadenes toma la acequia de Don Gonzalo. En el paraje de La Parra los azudes para las acequias de La Andelma en la M.D. y de la acequia de Los Charcos-Fatego en la M.I. En el Menjú se inicia el primero de los sistemas de azud y acequias para el riego en el histórico Valle de Ricote. En la M.D. La acequia de Charrara, continuada en su tramo final por el canal del heredamiento de Noria y Campillo. Y del azud en su M.I. arranca el tramo conjunto de las Acequias de Abarán y Blanca que a partir del estrecho de Las Canales en el paraje del Molino Papel se parte en acequia Principal de Abarán y acequia Mayor de Blanca.

Tras el estrecho del Solvente, se reconstruyó el tradicional azud para riego del que parte en su M.I. la acequia de Ulea, y de su M.D. la acequia de Ojós-Villanueva. Aguas más abajo, a unos 230 kilómetros del nacimiento de Segura, la presa de Archena que riega en la M.D. pero una hila de ella atraviesa, mediante sifón, a la M.I. al parque de Los Baños ${ }^{3}$. También en esa M.I. nos encontramos con la presa de Caravija y el canal del salto hidroeléctrico de La Sociedad Molinos del Segura, del que toma la acequia de Caravija. Más abajo del puente metálico que permite atravesar el río, en su M.D. arranca la presa y acequia de Alguazas, que se divide con el mismo nombre y con el de acequieta de Alguazas. En la pedanía archenera de la Algaida, en la M.I. de río figura la presa de Molina y la toma de esta acequia que suministra agua a los heredamientos de Lorquí y de Molina de Segura.

Finalmente en el estrecho de Las Pudingas está el Azud Mayor de la Huerta de Murcia (La Contraparada), en su M.I. arranca la acequia de Aljufía y de su M.D. la acequia de Alquibla. También en la M.I. toma antes de La Contraparada la acequia de Churra La Nueva. Estas tres acequias mayores conforman la red de aguas vivas de la Huerta de Murcia, a la que se suma toda un red de acequias menores para la distribución del agua a parajes y parcelas; completado este sistema con la red de aguas muertas de azarbes, landronas, meranchos y azarbetas. Ésta es la denominada Vega Media o Huerta de Murcia, dónde la amplitud del

\footnotetext{
3 "Presa de Archena, en término de Villanueva. Distancia al origen 230,48 km. De esta presa construida en mampostería hidráulica, toma por su margen derecha la acequia del mismo nombre que toma por una boquera abierta en la tierra sin revestimiento alguno, de 4 metros de ancha y 2 metros de alta. Esta acequia cuya longitud es de 7 kilómetros empieza regando en término de Villanueva, penetra después en el de Archena atravesando por medio de un túnel las alturas situadas al E. del Balneario de los Baños de Archena y termina en el paraje del Hurtado del mismo término vertiendo sus sobrantes en la acequia de Alguazas. En esta acequia hay instalados gran número de aparatos elevadores para dar riego a tierras situadas más altas y cuya superficie es superior a la que riega a portillo. De esta misma acequia, antes de penetrar en el túnel, arranca un hijuela que después de regar el Balneario atraviesa el río por un acueducto de madera y riega en la margen izquierda el parque de Los Baños de Archena y los terrenos de la rambla del Arco"(Arévalo Marco, 1932-1933, p. 64-65).
} 
valle y su escasa pendiente, permitían regar con un sólo azud, a mediados del siglo XIX, unas 94.002 tahúllas (Mancha, 1836), mientras que en el Valle de Ricote (de Abarán a Archena)se regaban 2.383 (Madoz, 1850).

\section{Infraestructuras para el riego por elevación con artilugios tradicionales y pequeños grupos motobomba. El riego en las laderas del Valle.}

Por encima del nivel o cota por la que discurren las acequias en la Vega Alta del Segura, quedan toda una serie de terrenos con la posibilidad de riego si se pudiera elevar el agua y retenerla en los nuevos terrazgos hasta que fuese aprovechada por los cultivos. Con este fin se acondiciona el terreno buscando la horizontalidad del área a regar, rompiendo la pendiente con aterrazamientos y construcción de muros de piedra seca "hormas" que permitan retener agua y suelo. Y lo más importante, se sitúan los necesarios artilugios elevadores de agua sobre acequias y regaderas en las vertientes del valle.Entre los que sobresalen las ruedas y contraruedas situadas escalonadamente en las laderas, y con las que se regaban en 1929, casi tres mil tahúllas. (Tabla 1).

La mayor parte de estos artilugios de elevación de agua eran ruedas de corriente baja, con canjilones en una o en las dos coronas (ruedas gravitatorias), conocidas también como azudas e incluso añoras. El otro grupo serían las norias de tiro o de sangre, incluidas las artes (de rosario o cremallera), que reciben el nombre de ceñas. También alguna molineta y eran más numerosas las bombas de mano. Lo habitual para escalar las laderas era situar una contraceña sobre el canal de agua elevada por una rueda de corriente baja. En ocasiones la contraceña elevaba a una pequeña balsa sobre la que se situaba otro ingenio, para elevar el agua a mayor altura (una contraceña más pequeña o una bomba de mano).

En el último tercio del siglo XIX varios de estos artilugios son sustituidos por motores de elevar agua (más volumen e incluso a más altura) ${ }^{4}$, se crean sociedades de regantes (comunidades civiles de bienes) con este objeto. Se aplican avances tecnológicos como máquinas de vapor, y motores de fuel-oil, de gas pobre, de gas-oil, y finalmente electromotores. Estos últimos relacionados con la creación de centrales hidráulicas en la red de Segura ${ }^{5}$. El primer tercio del siglo XX cuenta con mayor número de estas sustituciones, que implican un elevado gasto energético, pero amplía los regadíos.

\footnotetext{
${ }^{4}$ En la margen derecha de Segura, riega la asociación de regantes de la Aceña de Candelón. En su Juntamento de 26 de marzo de 1911 figura la siguiente propuesta : "Seguidamente expuso el hacendado D. José Martínez Velasco que sería de conveniencia y utilidad para todos los interesados que constituyen esta asociación sustituir la aceña o noria de que actualmente se valen para elevar agua, por un motor eléctrico de la fuerza necesaria para regar las fincas con mayor cantidad de agua, lo cual reportaría una gran economía con relación a lo que hoy cuestan los riegos a la par que se beneficiarían por la facilidad y prontitud con que se desarrrollaría el arbolado ..." (Gómez Espín, 1983a, p. 8).

${ }^{5}$ De Cieza a la Contraparada figuran más de quince saltos con sus centrales hidroeléctricas, base de la electrificación en la Vega Alta: Hoya García, Santo Cristo, El Gallego, La Cebolla, Bolvás, y El Menjú en Cieza. San José, Las Pilas, Los Sagrados Corazones y Soto Damian en Abarán. Piñera-Mase y Blanca en Blanca. El Solvente y el Galgo en Ulea y Ojós. Molinos de Segura y Río Muerto en Archena. (Arévalo Marco, 1932-1933, p. 38-42).
} 
Tabla 1. Artilugios elevadores de agua en la Vega Alta de Segura. Año 1929.

\begin{tabular}{|l|l|r|r|}
\hline Margen del río & Denominación cauce de toma & \multicolumn{1}{|c|}{$\begin{array}{c}\text { Núm. } \\
\text { Ingenios }\end{array}$} & \multicolumn{1}{c|}{$\begin{array}{c}\text { Riego en } \\
\text { tahúllas }\end{array}$} \\
\hline M. Derecha & Acequia del Salmerón & 1 & 60 \\
\hline M. Izquierda & Acequia Peralejo & 1 & 15 \\
\hline M. Derecha & Acequia de Berberín & 1 & - \\
\hline M. Izquierda & Acequia de Rotas & 3 & 115 \\
\hline M. Izquierda & Acequia de Esparragal & 1 & 3 \\
\hline M. Derecha & Acequia de D.Gonzalo & 7 & 170 \\
\hline M. Izquierda & Acequia del Horno & 18 & 209 \\
\hline M. Izquierda & Acequia de Los Charcos & 6 & 14 \\
\hline & Del Salmerón al Menjú & $\mathbf{3 8}$ & $\mathbf{5 8 6}$ \\
\hline M. Derecha & Acequia Charrara & 21 & 63 \\
\hline M. Derecha & Canal Noria y Campillo & 3 & 1 \\
\hline M. Izquierda & Tramo conjunto y Ac.PrincipalAbarán & 9 & 174 \\
\hline M. Izquierda & Acequia Mayor de Blanca & 29 & 255 \\
\hline & Del Menjú al Solvente & $\mathbf{6 2}$ & $\mathbf{4 9 3}$ \\
\hline M. Derecha & Acequia de Ojós-Villanueva & 3 & 9 \\
\hline M. Izquierda & Acequia de Ulea & 2 & - \\
\hline M. Derecha & Acequia de Archena & 12 & 338 \\
\hline M. Izquierda & Acequia de Caravija & 6 & 362 \\
\hline M. Derecha & Acequia de Alguazas & 11 & 411 \\
\hline M. Derecha & Acequieta de Ceutí & 10 & 170 \\
\hline M. Derecha & Acequieta de Alguazas & 2 & 36 \\
\hline M. Izquierda & Acequia de Molina y Subirana & 7 & 583 \\
\hline & Del azud de Ojós a la Contraparada & $\mathbf{5 3}$ & $\mathbf{1 . 9 0 0}$ \\
\hline Totales & Del Salmerón a la Contraparada & $\mathbf{1 5 3}$ & $\mathbf{2 . 9 7 9}$ \\
\hline
\end{tabular}

Fuente: Elaboración propia. A.C.H.S. Censo de norias para aprovechamientos agrícolas en la Cuenca de Segura. Año 1929.

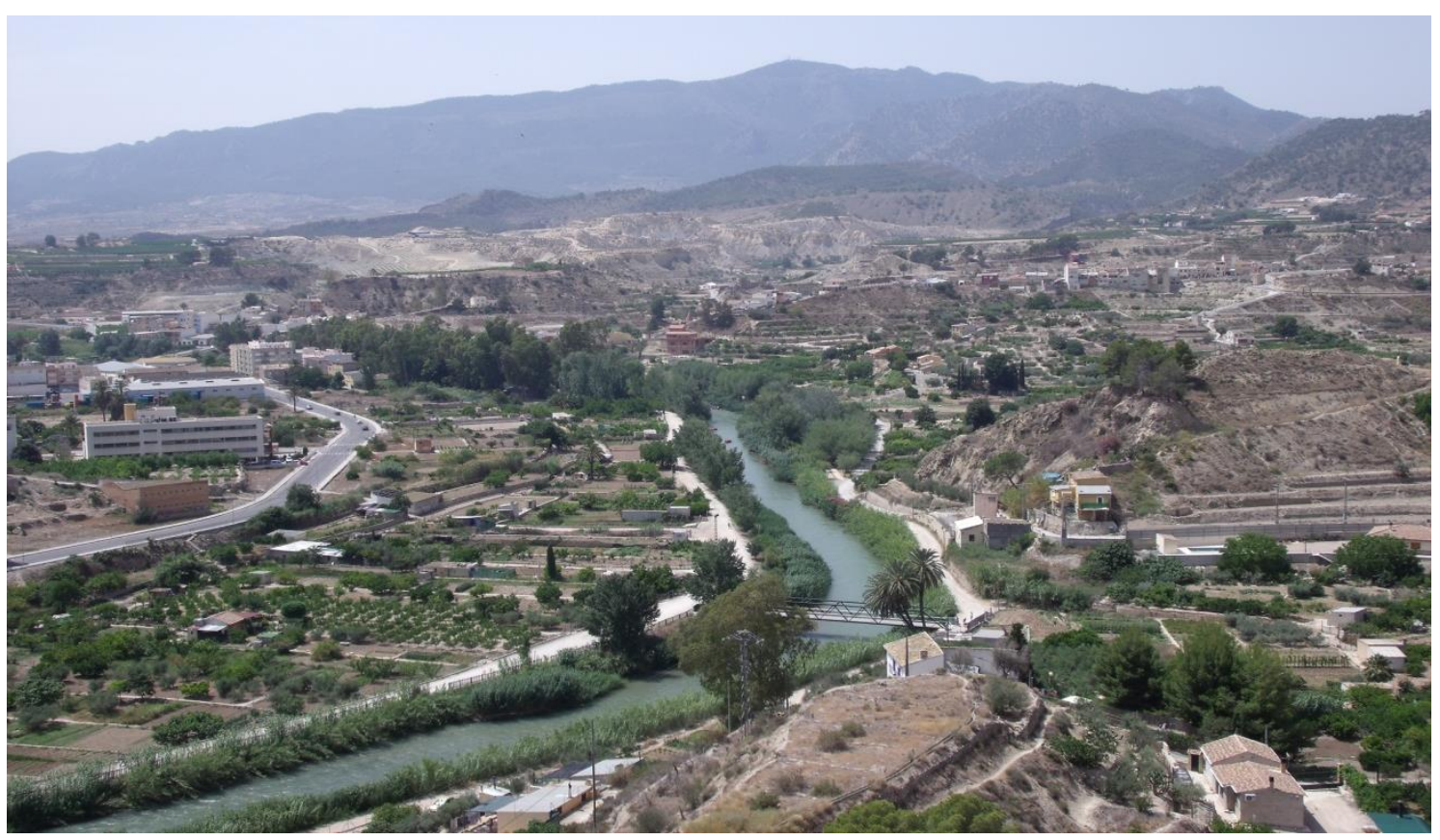

Fig.7. El riego en la cubeta de Abarán. Elevaciones de agua con ruedas y motores $(08 / 06 / 2014)$. 
Tabla 2. Superficies de riego según modalidad (gravedad o elevación) en la Vega Alta de Segura. (Tramo de presa del Cenajo al azud de Ojós). Año 2000.

\begin{tabular}{|l|l|r|r|r|}
\hline Margen & Denominación de la toma & $\begin{array}{l}\text { Riego por } \\
\text { gravedad (ha). }\end{array}$ & $\begin{array}{l}\text { Riego } \\
\text { elevación (ha) }\end{array}$ & \multicolumn{1}{c|}{ Total (ha) } \\
\hline M. D. & Acequia Picanas & 10,50 & - & 10,50 \\
\hline M. I. & Acequia Cenajo & 35,00 & - & 35,00 \\
\hline M. I. & Acequia Hondón y Chamorra & 28,80 & - & 28,80 \\
\hline M. I. & Acequia Maeso y Minas & 134,00 & 155,00 & 289,00 \\
\hline M. D. & Acequia Moarque y Torre Arenas & 68,00 & - & 68,00 \\
\hline M. D. & Acequia del Salmerón & 186,00 & 14,40 & 200,40 \\
\hline M. I. & Acequia del Puerto o del Vayo & 18,50 & - & 18,50 \\
\hline M. D. & Acequia de Cañaverosa & 26,00 & 64,00 & 90,00 \\
\hline M. I. & Acequia del Salto y Coto Minero & 28,45 & - & 28,45 \\
\hline M. I. & Acequia de Rotas & 328,47 & 43,27 & 371,74 \\
\hline M. D. & Acequia de Berberin & 44,61 & 22,70 & 87,31 \\
\hline M. D. & Acequia de Esparrgal & 119,07 & 9,66 & 128,73 \\
\hline & Tomas del río Segura en Calasparra & - & 93,93 & 93,93 \\
\hline & Almadenes & 1,15 & - & 1,15 \\
\hline M. D. & Acequia de D.Gonzalo & 170,97 & 37,48 & 208,45 \\
\hline M. I. & Salto del Progreso & 11,80 & - & 11,80 \\
\hline M. I. & Acequia del Horno & 161,92 & 199,80 & 361,50 \\
\hline M. D. & Acequia Andelma & 269,61 & - & 269,61 \\
\hline M. I. & Acequia de Los Charcos & 223,60 & 7,30 & 230,90 \\
\hline & Tomas del río Segura en Cieza & - & 459,09 & 459,09 \\
\hline M. D. & Acequia Charrara & 72,89 & 598,81 & 671,70 \\
\hline M.D. & Canal Noria y Campillo & 67,08 & - & 67,08 \\
\hline M. I. & Acequias de Abarán y Blanca & 170,40 & $2.077,32$ & $2.247,72$ \\
\hline & Tomas del río Segura en Blanca & - & 166,27 & 166,27 \\
\hline & & & & \\
\hline Total & & 2176,82 & $3.943,81$ & $6.120,63$ \\
\hline (\%) & & 35,57 & 64,43 & 100,00 \\
\hline F. & & & \\
\hline
\end{tabular}

Fuente: Elaboración propia. A.C.H.S. Signatura 17.472

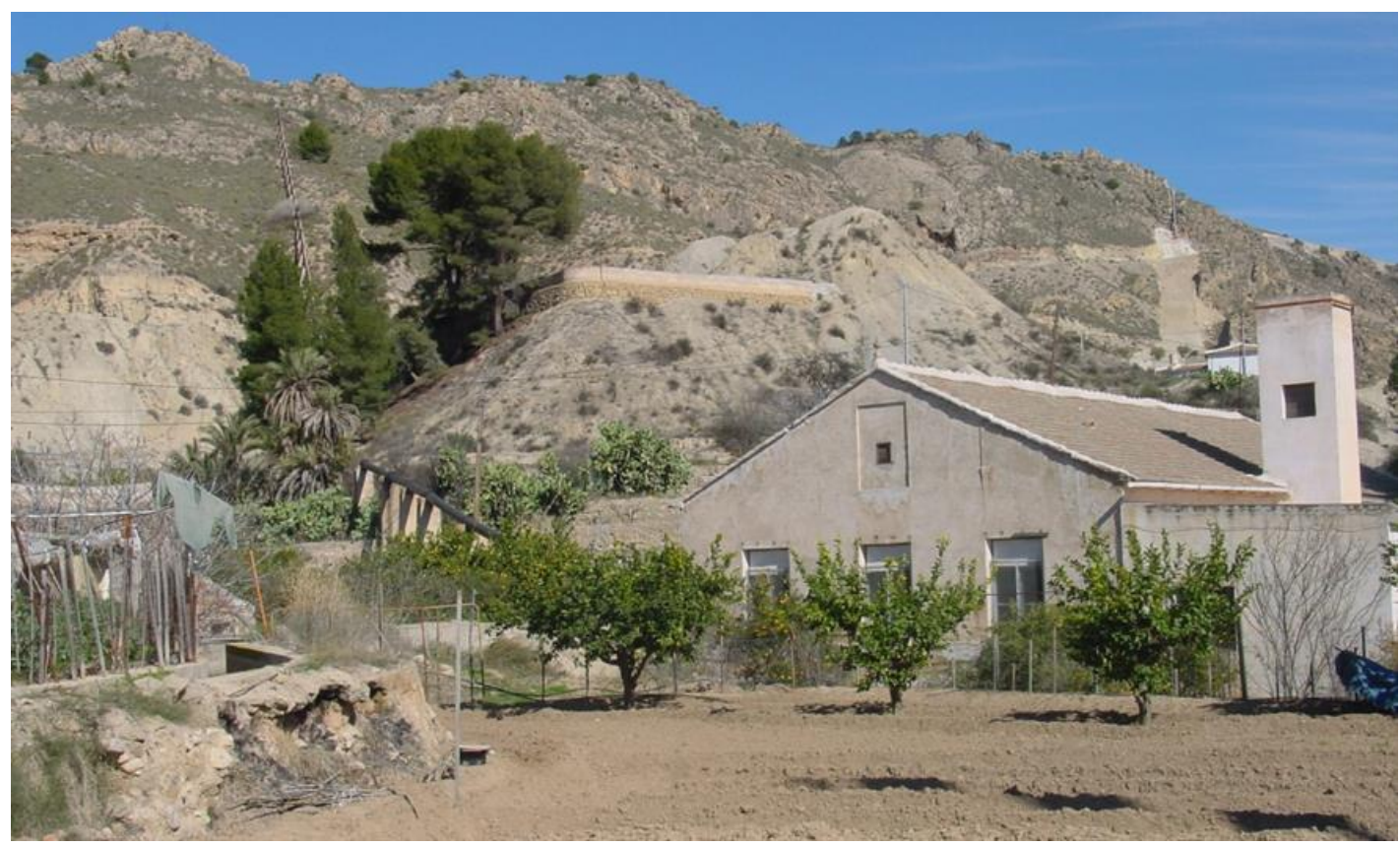

Fig.8. Elevación de aguas del Motor Resurrección. (200 1/seg a 135,4 metros de altura desde 1927 de forma continuada). (16/02/2005). 


\section{Infraestructuras para el riego por elevación con grandes grupos motobomba a las partes más altas del Valle y fuera de él}

El espacio regado del tramo alto del valle fluvial de Segura se queda pequeño para la gran demanda de frutas y hortalizas que se produce en esos años en España y en el extranjero, en fresco y sobre todo transformadas. El Coto arrocero se extiende ocupando los sotos de Segura en Hellín, Moratalla y Calasparra, hasta casi los Almadenes. En las huertas, las ciruelas "del Tío Caenas", junto al albaricoque de variedad "Búlida" y los melocotones "Maruja, Calabacero y Jeronimo" son la base de una industria transformadora en Calasparra, Cieza, y sobre todo en Abarán. Los cítricos se extienden por todo el valle de Ricote. Los oasis del rosario de huertas del valle constituyen una clara fuente de riqueza, a pesar del minifundio, (tras más de cuatrocientos años de división de la propiedad y de la explotación), pero siempre unidas la tierra y el agua. Se pagan bien ciertos productos tanto por las conserveras como por las manipuladoras en fresco. Si se continúa con la política de crear embalses para regular el Segura y con las mejoras tecnológicas (sobre todo grandes grupos motobomba y redes eléctricas), sería posible ampliar el regadío en las partes más altas del valle e incluso fuera de él. Impulsando agua desde las acequias o el río hasta los campos de secano sobre terrenos más llanos (como la Hoya del Campo o el Rellano) en los que introducir nuevos cultivos (como uva de mesa) y establecer explotaciones con marcos de plantación que permitan la mecanización de las labores.

Iniciativas como la de la Comunidad de Regantes del Motor Resurrección (2 de febrero de 1912), que es autorizada por el Heredamiento Regante de la Acequia Principal de Abarán a elevar de la cola de la acequia un caudal de 200 litros por segundo, a 135,4 metros de altura (hasta el Cabezo del Piricú o de la Mina), y desde allí por gravedad regar más de 670 hectáreas de tierras de secano y erial de los parajes de Casa Alcántara, Hoya del Campo, Vergeles, etc. A partir de 1927 se consigue elevar agua de forma continuada al Campo y marca un hito en la historia del regadío por elevación. Cambia la mentalidad de un pueblo que su área regada había estado más de 600 años constreñida al estrecho marco del valle (apenas de 60 a $120 \mathrm{ha}$ ), y que en sesenta años multiplica por diez esa superficie de riego, moderniza los sistemas de cultivo y aumenta la productividad.

Hasta mediados del siglo XX se vive bajo el espíritu del riego como fuente de "riqueza nacional ", el modelo del Motor Resurrección contagia al riego por elevación en la Vega Alta de Segura, con iniciativas como "Resurgir", "Progreso", "Esperanza", "El Porvenir", "Triunfo", etc., que explican como las aguas del Segura se usan para riego en la Vega Alta, hasta un tercio por gravedad (bajo acequia), y las dos terceras partes de la superficie regada, por elevación en las vertientes del valle y fuera de él. A nivel local, el pequeño riego es una fuente de diferenciación social y económica, se desarrolla una cultura del agua basada en el sistema azud-acequia como una comunidad de usuarios de una misma toma; a la que se asociaran las sociedades de impulsión de aguas para riego "motores", y aumenta la gobernanza de heredamientos y comunidades de regantes. Las mutaciones en los paisajes regados se deben a la regulación del régimen de Segura, a la expansión urbana de algunos núcleos invadiendo las huertas, y a la mejor respuesta de las áreas de nuevos regadíos a las exigencias de los mercados hortofrutícolas. 


\section{Agradecimientos}

Proyecto de investigación CSO2010-19947 (Subprograma GEO) "Uso eficiente y sostenible del agua en la Cuenca del Segura". Plan Nacional de Ciencia. Ministerio de Ciencia e Innovación. Ministerio de Economía y Competitividad. ESPAÑA.

\section{Referencias}

A.C.H.S. Signatura 758. Proyecto de obras de urgente ejecución para reconstrucción de los riegos en los términos municipales de Moratalla y Calasparra (Murcia) aguas arriba del Paraje de Cañaverosa. Murcia, 8 de noviembre de 1948. El Ingeniero D. Rafael Couchoud Sebastiá.

A.C.H.S. Signatura 17.472. Pliego de bases que ha de regir en la contratación de la asistencia técnica para el estudio y redacción del "Proyecto de modernización de regadíos de la Vega Alta hasta Ojós". Abril, 2005. Autor: D. Carlos Marco García.

Arevalo Marco, E. (1932-1933): Plan Nacional de Obras Hidráulicas. Año 1932-1933. Dirección de Obras Hidráulicas del Segura. Murcia. 346 pp. (Policopiado).

Banegas Ortiz, J.; Gómez Espín, J. Ma. (1992): “Consideraciones sobre el funcionamiento de ruedas de corriente elevadoras de agua en el tramo alto del Valle del Segura". Papeles de Geografía, $n^{\circ} 18$. Universidad de Murcia. Pp. 87-104.

Brunhes, J. (1902): L’ Irrigation ses conditions géographique, ses modes et son organization dans la Peninsule Ibérique et dans l' Afrique du Nord. C.NAUD editeur. Paris. 580 pp.

Calvo García-Tornel, F.; Gil Meseguer, E; Gómez Espín, J. Mª.; Lillo Carpio, M., Montaner Salas, E.(2009): Tradición y modernidad en la Vega Alta del Segura. Desarrollo Rural en el Siglo XXI: Nuevas orientaciones y territorios. XIV Coloquio de Geografía Rural. Murcia. 203-238.

García Avilés, J. Mª (2003): "Evolución histórica del regadío en el Valle de Ricote“. Segundo Congreso Turístico Cultural Valle de Ricote. Consejería de Turismo y Ordenación del Territorio de la CARM. Pp. 183-216.

Gil Meseguer, E. (2006): "Los paisajes agrarios de la Región de Murcia”. Papeles de Geografía, $n^{\circ}$ 43. Enero-Junio de 2006. Universidad de Murcia. 19-30.

Gil Meseguer, E.; Gómez Espín, J. Ma . (1985): "Modificaciones del paisaje rural de la Vega Alta del Segura" Áreas. Revista de Ciencias Sociales, $n^{\circ}$ 5. Editora Regional. Universidad de Murcia. Pp. 22-36.

Gil Meseguer, E.; Gómez Espín, J.Ma . (2014): “Tradición y modernidad en los regadíos históricos del Valle de Ricote (Región de Murcia-España)". Actas del III Congreso de la Red de Investigadores Sociales sobre Agua (RISSA). Guanajuato-México. Pp. 1-26.

Glick, T. F. (1988): Regadío y sociedad en la Valencia medieval. Del Cenia al Segura. Valencia. 413 pp.

Gómez Espín, J.Mª (1983): Abarán, centro de producción y comercialización de productos agrarios. Caja de Ahorros Provincial de Murcia. Obra Social de la CAM. Excmo. Ayuntamiento de Abarán. 195 pp.

Gómez Espín, J.Ma. (1983a): La buella del riego en el paisaje de Abarán. El regadío tradicional. Edita Grupo Abarán V Centenario. 19 pp. 
Gómez Espín, J.Ma. (2012): Elevación de aguas para riego en la Cuenca de Segura. Cien años del Motor Resurrección (1912-2012). Regional Campus of International Excellance "Campus Mare Nostrum". Murcia. 143 pp.

Gómez Espín, J. Mª; Gil Meseguer, E. (2007): " Tradición y modernidad en el Valle de Ricote: Los paisajes regados de la margen izquierda del Segura". IV Congreso Internacional Valle de Ricote. Pp. 125-138.

Herin, R. (Reedición 2012): Las Huertas de Murcia. (Traducción y edición por la Academia Alfonso X el Sabio). Murcia. 215 pp.

Hermosilla Plá, J. (Dir) (2010): Los regadios bistóricos españoles. Paisajes culturales, paisajes sostenibles. Ministerio de Medio Ambiente, Medio Rural y Marino. Madrid. 608 pp.

Linarejos Cruz, M.; Díaz Ortín, R. (2007): "Estudio del paisaje cultural del Valle de Ricote. Murcia.”. IV Congreso Internacional Valle de Ricote. Pp. 57-68.

Maas, A.; Anderson, R.L. (2010): Los desiertos reverdecerán. Estudio comparativo de la gestión del riego en el Mediterráneo español y en el Oeste norteamericano, Generalitat Valenciana. 436 pp.

Madoz, P. (1850): Diccionario Geográfico-Estadístico-Histórico de España y sus posesiones de Ultramar. (Edición facsímil de lo referente a Región de Murcia). Consejería de economía, Industria y Comercio de la CARM. Murcia. Año 1989. 200 pp.

Martínez Lucas, V.; Gómez Espín, J. Ma . (2013): “Aprovechamiento integral de la Fuente del Ojo (Cieza-Murcia)". Papeles de Geografía, n57-58. Universidad de Murcia (edit.um). Pp. 161-178.

Martínez Soler, J. J. (2002). "Las norias del Valle de Ricote". I Congreso Turístico Cultural $V$ alle de Ricote. Consejería de Turismo y Ordenación del Territorio de la CARM. Pp. 60-72.

Montaner Salas, E. (1981): Norias, aceñas, artes y ceñiles en las Vegas Murcianas del Segura y Campo de Cartagena. Editora Regional de Murcia. 117 pp.

Montaner Salas, E.; Pastor Campuzano, M.; Gómez Espín, J. Ma. (2012): “Cultura de la acequia y de los artilugios elevadores de agua. Tramo del Segura desde el Azud de Ojós a la Contraparada”, en Gómez Espín, J.Mª y Hervás Avilés, R. Mª (Coord.) Patrimonio bidráulico y cultura del agua en el Mediterráneo. Fundación Séneca. AECID. Campus Mare Nostrum. Murcia. Pp. 51-75.

Palerm Viqueira, J.; Martínez Saldaña, T. (Editores) (2009): Aventuras con el Agua. La administración del agua de riego. Historia y Teoría. CONACYT. Colegio de Posgraduados. Texcoco México. 435 pp.

Rivera, J. A. (2009): La cultura de la acequia. Agua, tierra y comunidad en el Suroeste de los Estados Unidos de América. Universidad de Valencia. 309 pp. 